\title{
Application and comparison of NSGA-II and MOPSO in multi-objective optimization of water resources systems
}

\author{
Ali Hojjati ${ }^{1}$, Mohsen Monadi $^{2 *}$, Alireza Faridhosseini ${ }^{1}$, Mirali Mohammadi ${ }^{3}$ \\ ${ }^{1}$ Department of Water Engineering, Faculty of Agriculture, The Ferdowsi University of Mashhad, Iran. \\ 2 Department of Civil Engineering., Faculty of Engineering., Urmia University, P O Box 165, Urmia 5756115311, Iran. \\ ${ }^{3}$ Department of Civil Engineering (Hydraulic Structures \& River Mechanics), Faculty of Engineering, Urmia University, Iran. \\ * Corresponding author. E-mail: mohsen.monadi@gmail.com
}

\begin{abstract}
Optimal operation of reservoir systems is the most important issue in water resources management. It presents a large variety of multi-objective problems that require powerful optimization tools in order to fully characterize the existing trade-offs. Many optimization methods have been applied based on mathematical programming and evolutionary computation (especially heuristic methods) with various degrees of success more recently. This paper presents an implementation and comparison of multi-objective particle swarm optimization (MOPSO) and non-dominated sorting genetic algorithm II (NSGA-II) for the optimal operation of two reservoirs constructed on Ozan River catchment in order to maximize income from power generation and flood control capacity using MATLAB software. The alternative solutions were based on Pareto dominance. The results demonstrated superior capacity of the NSGA-II to optimize the operation of the reservoir system, and it provides better coverage of the true Pareto front than MOPSO.
\end{abstract}

Keywords: NSGA-II; MOPSO; Multi-objective optimization; Flood control; Hydropower.

\section{INTRODUCTION}

Numerous engineering optimization problems are so complex and troublesome; therefore they cannot be solved by traditional optimization techniques. The operation of reservoir system is a multi-objective problem and a difficult task to estimate reservoir operation policies that maximize all the benefits supplied by these reservoirs and also minimize their invisible impacts. The curse of dimensionality is a common problem for classical methods, especially for four reservoir systems and more. Complexity of the optimization model of multi-objective operation systems is the main cause of more interest in the use of heuristic methods among researchers, because these methods are able to find appropriate responses even when functions are non-linear, discontinuous and non-derivable.

Over the past years, several optimization techniques and multi-objective evolutionary algorithms have been developed and applied to optimize reservoir operation. These include Linear Programming (LP add 1 reference); Nonlinear Programming (NLP add 1 reference); Dynamic Programming (DP add 1 reference); Stochastic Dynamic Programming (SDP add 1 reference); Multi-objective differential evolution algorithm (MDEA); and Heuristic Programming such as Genetic Algorithm (GA) and Particle Swarm Optimization (PSO) analyze multi-objective optimization problems and provide useful insight about solutions that are generated using an populationbased approach. Schaffer (1985) proposed an extension of the simple GA (SGA) to accommodate vector-valued fitness measures, which he called the Vector Evaluated Genetic Algorithm (VEGA). After him, several researchers have been studying in this field and different methods with different capabilities were developing that many of them were presented in an overview and tutorial by Konak et al. (2006). NSGA-II was developed by Kalyanmoy et al. (2002) and till date several variants and applications for NSGA II have been developed (Chang and Chang, 2009; Ishibuchi et al., 2008; Malekmohammadi et al., 2011). Kalyanmoy and Jain (2012) proposed and applied MONSGA-II to a number of many-objective test problems with three to 10 objectives (constrained and unconstrained) and compared with a recently EMO algorithm (MOEA/D, add reference). The results reveal difficulties of MOEA/D in solving large-sized and differently-scaled problems, whereas MONSGA-II was reported to show a desirable performance on all used test-problems. An improved MO-NSGA-II with enhanced mating selection was used for many-objective optimization by Chen and Chiang (2014). Rio et al. (2010) applied an improved NSGA-II based on a novel ranking scheme to the problem of classifying types of leukemia based on microarray data. Results of comparative tests showed that the improved algorithm performs well on large populations.

MOPSO was proposed by Moor and Chapman (1999) to optimize more than one objective functions and till now many variants and applications for MOPSO have been developed. Baltar and Fontane (2006a, 2006b) have been used MOPSO variant to minimize deviations from outflow water quality (targets of: temperature, dissolved oxygen, total dissolved solids and $\mathrm{pH}$ ). They also presented an application of an evolutionary optimization algorithm for multi-objective analysis for reservoir operations and planning. Reddy and Kumar (2007, 2009) presented and applied Elitist-Mutation operator with MOPSO (EM-MOPSO) to find minimization of the sum of squared deviations for irrigation, maximization of hydropower production and satisfaction level of downstream river water quality requirements. Also, they used an Elitist-Mutated MOPSO (EM-MOPSO) to maximize hydropower production and minimize annual sum of squared of irrigation release from demands. Shuai et al. (2012) applied modified MOPSO to minimize highest water level, releasing peak discharge, difference of water level after flood season and flood control level. Eberhart and Kennedy (1995) introduced a new form of particle swarm optimizer. Ostadrahimi et al. (2011) improved the performance of the standard particle swarm optimization algorithm and incorporated a new strategic mechanism called multiswarm algorithm and used for multi-objective reservoir operation rules. Fallah-Mehdipour et al. (2011) presented three multiobjective optimization methods based on multi-objective parti- 
cle swarm optimization (MOPSO) algorithm. To evaluate these methods, they considered bi-objective mathematical benchmark problems. Results show that all proposed methods are successful in finding near-optimal Pareto fronts. Yang (2012) proposed a new particle swarm optimization algorithm solving hierarchy multi-objective problems and applied it to optimize the operation of hydropower stations. However, some other extensive reviews of different available techniques can be found elsewhere (Adeyemo, 2011; Ajibola and Adewumi, 2014; Bianchi et al., 2009). Kumar and Minz (2014) provided a proper concept of particle swarm optimization and the multi-objective optimization problem in order to build a basic background with which to conduct multi-objective particle swarm optimization. Patil and Dangewar (2014) presented a comprehensive review of a multi-objective particle swarm optimization (MOPSO) reported in the specialized literature. Yusoff et al. (2011) proposed an overview on NSGA-II optimization techniques of machining process parameters. Based on the above techniques, in this paper, application of NSGA-II and MOPSO algorithms in operation of two-reservoir systems to maximize incomes due to the hydropower sale and flood control is proposed.

\section{MATERIALS AND METHODS}

Multi-objective optimization is an important part of multiple criteria decision making. It has been applied in many fields of science, including engineering, economics and logistics, where optimal decisions need to be taken in the presence of tradeoffs between two or more conflicting objectives. In the optimization problems with incomplete data and information or restricted calculation capacity meta-heuristic is a robust procedure (Blum and Roli, 2003). Meta-heuristics sample a set of solutions which is excessively enormous to be entirely demonstrated. In comparison with another optimization algorithms and iterative methods, meta-heuristics do not guarantee a globally optimal solution on some class of problems (Kennedy and Eberhart, 1995). Many meta-heuristics carry out some forms of stochastic optimization, therefore the solution found is conditional on the set of random variables generated. Metaheuristics can frequently find excellent solutions with less calculative attempt than optimization algorithms, iterative methods, or simple heuristics by searching over a large set of feasible solutions. So, meta-heuristics are applicable methods for optimization problems. Several books and survey papers have been published on the subject. NSGA-II and MOPSO are the well-known meta-heuristic optimization methods for multi-objective optimization in water resource management. For a nontrivial multi-objective optimization problem, there is not a single solution that simultaneously optimizes each objective. Therefore, the objective functions are mentioned to be contradictory, and there are a number of Pareto optimal solutions. If none of the objective functions can be enhanced in value without humiliating some of the other objective values the solution is called non-dominated Pareto optimal. Without extra subjective precedence information, all Pareto optimal solutions are taken into account equally well. The aim is to find a typical set of Pareto optimal solutions, and/or determine the trade-offs in gratifying the distinctive objectives, and/or finding a single solution that satiates the subjective priorities of a decision maker (DM).

\section{Multi-objective particle swarm optimization}

Swarm Intelligence (SI) is mainly defined as the behavior of natural or artificial self-organized, decentralized systems.
Swarms interact locally with each other or with external agents, i.e. environment, and can be in the form of bird flocks, ants, bees etc. Introduced by Srinivas and Kalyanmoy (1994) for optimizing continuous nonlinear functions, Particle Swarm Optimization (PSO) defined a new era in SI. PSO is a population based method for optimization. The population of the potential solution is called as swarm and each individual in the swarm is defined as particle. The particles in the swarm search their best solution based on own experience and the other particles of the same swarm. PSO started to hold the grip amongst many researchers and became the most popular SI technique soon after getting introduced, but due to its limitation of optimization only of single objective, a new concept MultiObjective PSO (MOPSO) was introduced, by which optimization can be performed for more than one conflicting objectives simultaneously. As mentioned, MOPSO was proposed by Moor and Chapman (1999) to optimize more than one objective functions. In MOPSO instead of a single solution a set of solutions are determined, also called Pareto optimal set. The framework of MOPSO is shown in Figure 1.

\section{Non-dominated sorting genetic algorithm-II}

NSGA-II is the latter version of the popular "Non-dominated sorting genetic algorithm" developed in 2002 by Srinivas and Kalyanmoy (1994) to solve non-convex and non-smooth single and multi-objective optimization problems. Compared to NSGA it is a useful algorithm which has an improved mating mechanism dependent upon the crowding distance and performs constraints using an adapted explanation of dominance without the use of penalty functions. The population initialization is done as before. At the beginning, a zero level is allocated to all non-dominated individuals. During elimination of the individuals from the population, the lately non-dominated solutions are allocated level one. This procedure goes on up to the time which all solutions have been allocated a non-domination level. Parents selecting process is carried out using binary tournament selection on the basis of the lesser rank and greater crowding distance. The next step includes off-springs generating from the selected population using crossover and mutation operators, which will be discussed in the following. Finally, the present off-springs and population are sorted another time dependent upon the non-domination and just the best individuals with the number of the population size $(\mathrm{P})$. The flowchart of the NSGA-II is shown in Figure 2.

\section{Case study}

The two proposed techniques are applied to find nondominated solutions for the operation of two reservoirs system in the Ozan catchment. Ostoor and Pirtaqi dams are located in the Ozan catchment with longitude coordinate $48^{\circ} 53^{\prime} 0.59^{\prime \prime}$ and $41^{\circ} 13^{\prime} 51.6^{\prime \prime}$ eastern and latitude coordinate $37^{\circ} 30^{\prime} 24.7^{\prime \prime}$ and $37^{\circ} 28^{\prime} 4.4^{\prime \prime}$ northern, respectively. Their locations are shown in Figure 3.

The case study includes two consecutive reservoirs with a hydroelectric power plant in the downstream of each dam. The inflow of Pirtaqi dam is equal to the total discharge from the Senghor Chay River, output water from the turbines and overflow from Ostoor dam. A schematic of the optimization problem is shown in Figure 4.

According to the electricity consumption in different seasons, the selling price of electricity in each season is different. So that, in spring and summer due to greater demand, electricity costs will be higher than autumn and winter. On the other hand, 


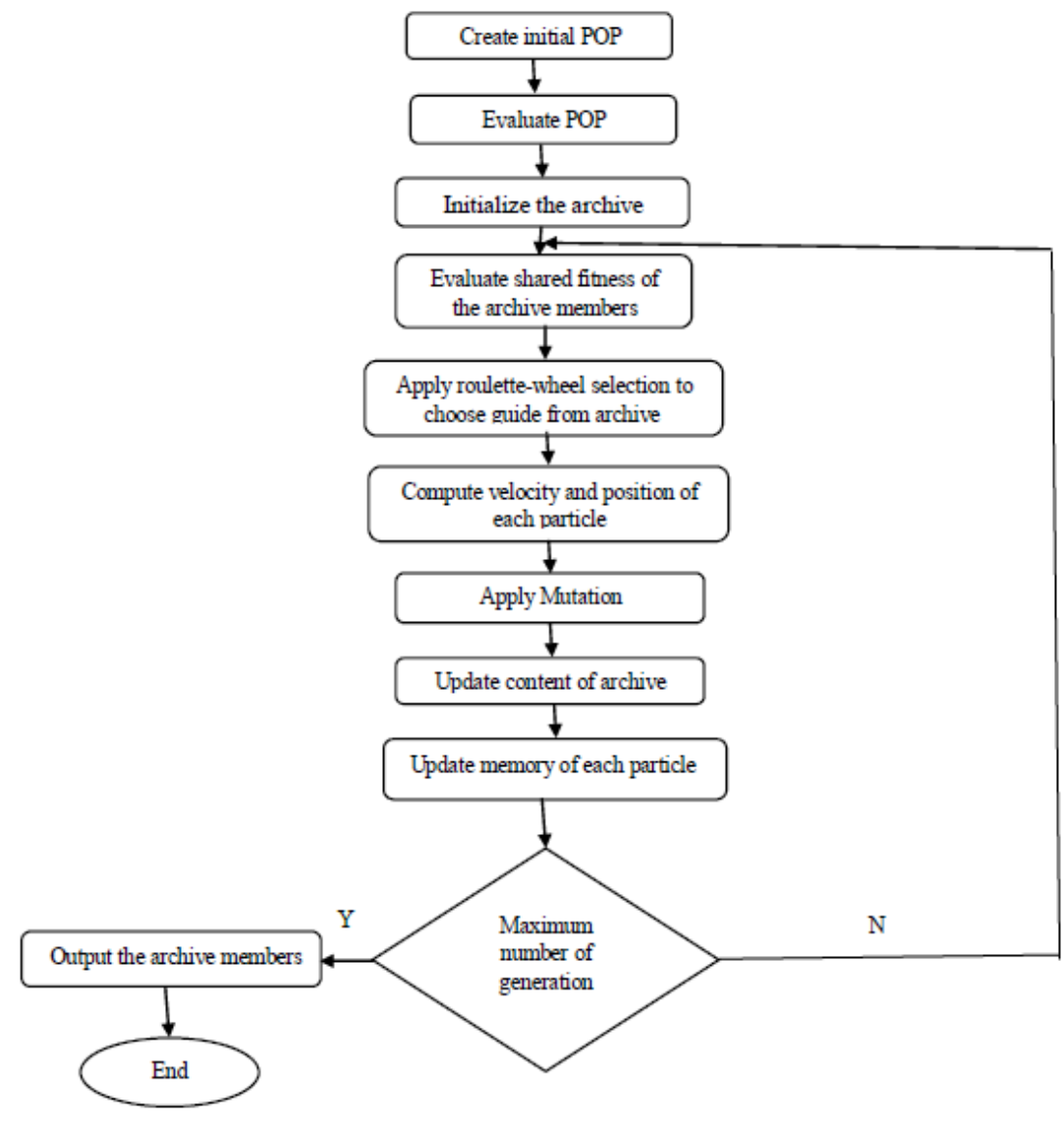

Fig. 1. Flowchart of multi-objective particle swarm optimization.

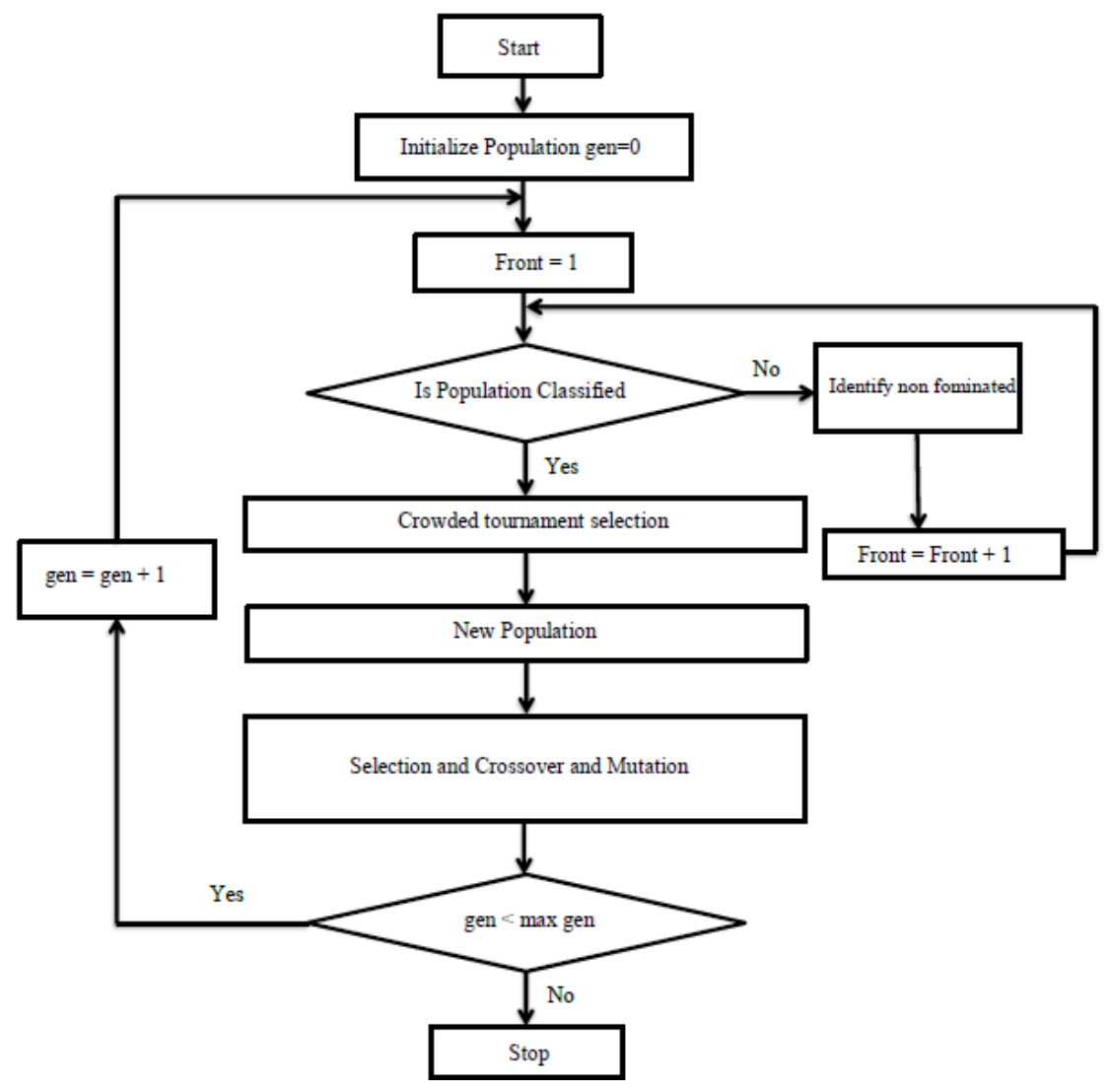

Fig. 2. Flowchart of NSGA-II. 


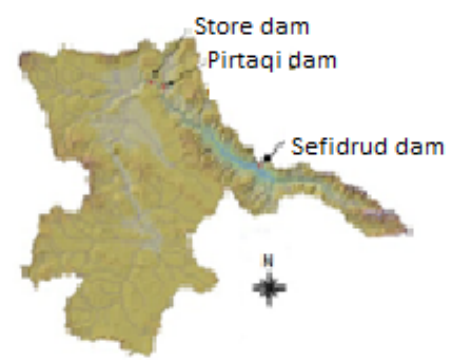

Fig. 3. The position of two reservoirs system.

in February, March, April and May the river inflows into the reservoir have highest discharge so these four months are considered as the flood months. Therefore, because flood control the normal water level should be kept on the lowest level. The objective functions used in the model are as below.

$$
\begin{aligned}
& f(1)=\operatorname{Maximize} \sum_{i=1}^{n} \sum_{t=1}^{T} P W P^{t} \times P E_{i}^{t} \\
& f(2)=\text { Maximize } \sum_{i=1}^{n} \sum_{t=1}^{\mathrm{T}} C^{t} \times\left(S_{i}^{n}-S_{i}^{t}\right)
\end{aligned}
$$

Equations (1) and (2) are for maximization of hydroelectric energy production and flood storage volume, respectively, where $T$ is the time horizon (12 months) of Exploitation model, PWP is proceeds from the sale of a unit of the produced energy in month $\mathrm{t}$ in Rial/MWh, $C^{t}$ is constant coefficient of flood in month $\mathrm{t}$ that in the flood months is equal to 1 and in the other months is zero, $S_{i}^{n}$ is reservoir volume $i$ at normal level in terms of cubic meters, $S_{i}^{t}$ is reservoir volume i in terms of cubic meters in the beginning of the month $t, P E_{i}^{t}$ is energy generated in the reservoir $i$ in month $\mathrm{t}$ in Watts and $\mathrm{n}$ is the number of the under investigation reservoirs.

Constraints used in the model include the following three parts:

\section{a. Water balance in the reservoir}

$$
\begin{aligned}
& S_{1}^{t+1}=S_{1}^{t}+I_{1}^{t}+P_{1}^{t}-E_{1}^{t}-R_{1}^{t}-S_{\text {Spill }}^{t} \\
& S_{2}^{t+1}=S_{2}^{t}+I_{2}^{t}+I_{3}^{t}+P_{2}^{t}-E_{2}^{t}-R_{2}^{t}-S_{\text {Spill }}^{t} \\
& S_{\text {dead }} \leq S_{t} \leq S_{\max }
\end{aligned}
$$

where $S^{t}$ and $S^{t+1}$ are storage of each reservoir at the beginning and end of the time period $t$, respectively, $I_{1}^{t}$ and $I_{2}^{t}$ are inflow discharges to the reservoirs, $P_{1}^{t}$ and $P_{2}^{t}$ are the rainfall over the reservoirs, $E_{1}^{t}$ and $E_{2}^{t}$ are the evaporation from the reservoirs, $R_{1}^{t}$ and $R_{2}^{t}$ are the output water of the power plant, Spill $l_{1}^{t}$ and Spill $_{2}^{t}$ are the overflow water from the reservoirs in month $\mathrm{t}$, in reservoir 1 and 2 respectively. Also, $I_{3}^{t}$ is the inflow discharge of the SenghorChay River into the reservoir 2 in month $t$. Equation (5) shows that the storage of the reservoir $\left(S_{t}\right)$ in each time period is limited to the maximum storage $\left(S_{\max }\right)$ and dead storage $\left(S_{\text {dead }}\right)$.

\section{b. Water Release Restrictions}

$R_{\min } \leq R_{t} \leq R_{\max }$

Equation (6) indicates the restriction on the water releases to the power plants which at $R_{\min }$ it is equal to zero and at $R_{\max }$ it is equal to $50 \mathrm{~m}^{3} / \mathrm{s}$ and $40 \mathrm{~m}^{3} / \mathrm{s}$ for Pirtaqi and Ostoor dams, respectively. In this equation, $R$ is water release in $\mathrm{m}^{3} / \mathrm{s}$.

\section{c. Minimum downstream flow to protect the environment \\ $R+$ Spill $\geq M R D$}

Equation (7) indicates the minimum downstream flow to protect the environment where MRD is the minimum requirement of downstream that for each of the reservoir this amount is equal to the highest amount of monthly discharge in the month, that during 42 statistical years, has the lowest average discharge and for Ostoor and Pirtaqi reservoirs are 42.85 and 66.96 million cubic meters (MCM), respectively. In this equations (6) and (7) $\mathrm{R}$ is water release in $\mathrm{m}^{3} / \mathrm{s}$.

\section{Penalty functions}

In the restriction of the reservoir balance, the storage of the reservoir $\left(S_{t}\right)$ should not be less than the dead storage of the reservoir $\left(S_{\text {dead }}\right)$. Also in the restriction of the water releases $R_{t}$ should be less than $R_{\min }$ and in the restriction of the minimum requirements of downstream for environmental issues, the amount should not be less than the minimum flow required for the purpose. If the above conditions are not satisfied the following equations for these restrictions will apply as penalty functions, respectively.

The penalty functions of the storage of water in the reservoirs, water releases to the power plants and the minimum requirements of downstream are as follows.

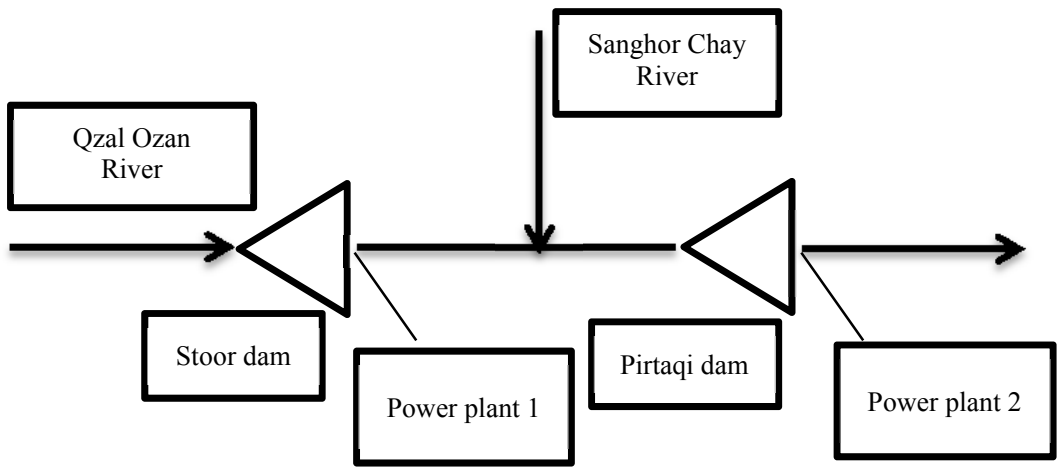

Fig. 4. Schematic of the optimization problem. 
if $S_{t}^{1}>S_{\text {dead }} \rightarrow P_{s}=I_{t=1}^{T}\left(1+K\left(S_{t}-S_{\text {dead }}\right)^{2}\right)$

if $R_{t}^{1}>R_{\min } \rightarrow P_{R}=I_{t=1}^{T}\left(1+K\left(R_{t}-R_{\min }\right)^{2}\right)$

if $R_{t}+\operatorname{Spill}_{t}^{1}>M R D \rightarrow P_{R}=I_{t=1}^{T}\left(1+K\left(R_{t}-R_{\min }\right)^{2}\right)$

where $P_{S}$ is the penalty function for storage and $P_{R}$ is the penalty function for release and coefficient $\mathrm{K}$ is penalty coefficient and has a large scalar value as $1 \times \mathrm{e}^{10}$ which in case of nonconformity of the constraints of the model, and considering that the algorithm is seeking to minimize the objective functions, is added to the objective functions. This amount is large enough that the probability of the member presence in the next generations come down certainly and eliminated practically. All of the variables are explained before.

\section{RESULTS AND DISCUSSION}

Non-dominated sorting genetic algorithm II (NSGA-II)

The objective functions for NSGA-II are as equations (11) and (12).

$$
\begin{aligned}
& f(1)=\text { Minimize }-\left(\sum_{i=1}^{n} \sum_{t=1}^{T} P W P^{t * P E_{i}^{t}}\right) \\
& f(2)=\text { Minimize }-\left(\sum_{i=1}^{n} \sum_{t=1}^{T} C^{t} *\left(S_{i}^{n}-S_{i}^{t}\right)\right)
\end{aligned}
$$

To optimize the objective functions, each chromosome is made of 24 genes, one month time period and planning of the reservoir operation for a year are considered and the population size is equal to 20 . At the first, the initial population is simulated and their fitness function determined which is called parent population. Then the parents are placed in case of pair in 15 mating pools. Selection of being pair or the number of mating pools that are often equal to half of the initial population, can be different. In this study tournament selection, with size 2 is used. Then, based on the superiority of rank and fitness between both parents who placed in the pool, crossover and mutation operators are applied on the pair of them. In the NSGA-II a crossover operator called SBC, which is a search engine similar to dual single point crossover, has been used. According to the mentioned crossover and mutation operators, we considered $P_{\text {mutation }}=0.1, P_{\text {crossover }}=0.9$, mutation distribution parameter $=50$ and crossover parameter $=3$. After trial and error, the number of generations produced in the model, which is also considered as stop condition, is equal to 400 generations.

\section{Multi-objective particle swarm optimization (MOPSO)}

In this study, maximum number of iteration was considered as stop condition for the MOPSO algorithm. Before setting the parameters of the algorithm, determination of the initial population size is very important to start the algorithm. Therefore, at the first step five different population sizes of 20, 50, 100, 150 and 200 were considered and population size of 200 showed the greatest benefit for objective functions. The input parameters taken for determination of the size of the population are as follows: $C_{1}=C_{2}=2, w_{\text {damp }}=0.99, w=0.8, \gamma=2$ and $\beta=2$. Then considering the population size of 200 , the inertia coefficient in the range of 0.4 to 0.9 was evaluated, which $w=0.5$ has been earned the most benefit in the objective functions. With regard to the optimal size of the population and inertia coefficient $(w)$, optimal amount of individual learning coefficient $C_{1}$ and global learning coefficient $C_{2}$ are equal to 1.5 and 2 , respectively. And the other parameters such as inertia weight damping ratio $\left(w_{\text {damp }}\right)$ and selection pressures $(\gamma$ and $\beta)$ were constant according to the past experiences and after applying many changes in the population and parameters and run the algorithm for many times, the best answer was obtained. The appropriate distribution at Pareto front and the maximum value of the objective function are considered as the criteria to determine the optimum solution.

Finally, MOPSO and NSGA-II have been applied with 400 iterations and 400 generations as stop conditions, respectively. The Pareto fronts of both models are shown in Figures 5 and 6 and the solutions for both models are extended as well as in a narrow range of values of the objective functions. In these Figures the reason of the difference between Pareto curves from the two methods is because of the minimization of the objective function multiplied by the negative sign in the NSGA-II model, and as it can be seen from Figure 5 the values are negative.

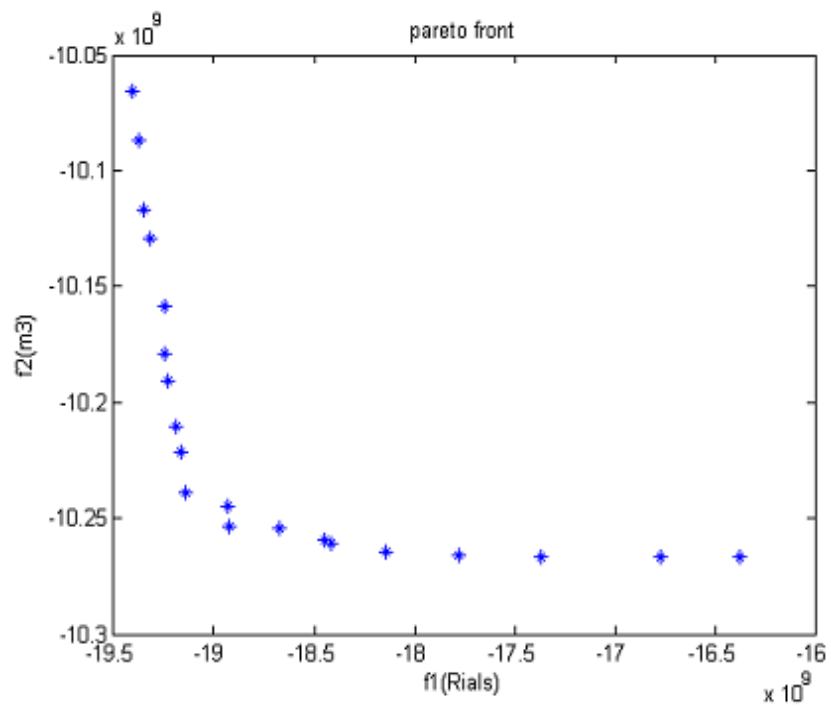

Fig. 5. Pareto optimal points obtained by NSGA-II model.

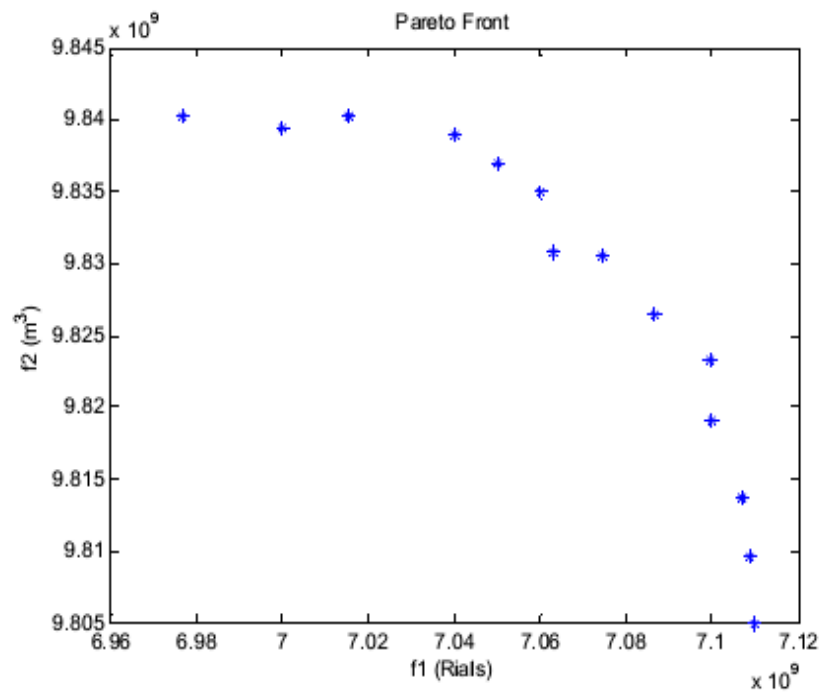

Fig. 6. Pareto optimal points obtained by MOPSO model. 
In the NSGA-II model and in power plant of Ostoor (Pirtaqi) reservoir, the highest income and the lowest income are obtained in August and March February), respectively. In the MOPSO model in Ostoor (Pirtaqi) reservoir, the highest and lowest incomes are obtained in July-August and FebruaryMarch, respectively. There is more demand for electricity in summer than in winter, thus there is more need to produce energy in summer than in winter. So, the obtained income in both methods in summer is more than in winter. The price of each unit of energy and the total income in each month is pro- vided in Tables 1 and 2, respectively.

Considering the second objective function that maximizes storage of the reservoir in the flood months, it should be noted that in February to May and in each of Ostoor and Pirtaqi reservoirs, the volume of the reservoir is kept empty in order to control the likely floods (Tables 3 and 4 for both models).

The results of the two algorithms are presented and compared in Table 5, which demonstrated the superior capacity of the NSGA-II for optimizing the operation of the reservoir system than MOPSO algorithm.

Table 1. The price of each unit of energy and the total income of each month in the NSGA-II model.

\begin{tabular}{|c|c|c|c|}
\hline $\begin{array}{l}\text { Total income in Pirtaqi } \\
\text { reservoir (MRial) }\end{array}$ & $\begin{array}{l}\text { Total income in Ostoor } \\
\text { reservoir (MRial) }\end{array}$ & $\begin{array}{c}\text { Selling price of each MWh of } \\
\text { energy (MRial) }\end{array}$ & $\begin{array}{c}\text { Month shift this column to the very } \\
\text { right }\end{array}$ \\
\hline 298.65 & 105.96 & 0.046 & October \\
\hline 299.86 & 99.88 & 0.046 & November \\
\hline 370.92 & 144.26 & 0.046 & December \\
\hline 361.34 & 103.78 & 0.044 & January \\
\hline 287.30 & 105.95 & 0.044 & February \\
\hline 268.87 & 96.99 & 0.044 & March \\
\hline 372.25 & 130.20 & 0.049 & April \\
\hline 555.29 & 189.02 & 0.049 & May \\
\hline 594.59 & 213.45 & 0.049 & June \\
\hline 638.15 & 248.99 & 0.057 & July \\
\hline 593.51 & 261.43 & 0.057 & August \\
\hline 519.94 & 228.86 & 0.057 & September \\
\hline
\end{tabular}

Table 2. The price of each unit of energy and the total income of each month in the MOPSO model.

\begin{tabular}{|c|c|c|c|}
\hline $\begin{array}{l}\text { Total income in Pirtaqi } \\
\text { reservoir (MRial) }\end{array}$ & $\begin{array}{l}\text { Total income in Ostoor } \\
\text { reservoir (MRial) }\end{array}$ & $\begin{array}{l}\text { Selling price of each MWh of } \\
\text { energy (MRial) }\end{array}$ & Month same as Table 4 \\
\hline 288.67 & 123.77 & 0.046 & October \\
\hline 269.96 & 89.14 & 0.046 & November \\
\hline 340.86 & 174.27 & 0.046 & December \\
\hline 324.34 & 113.53 & 0.044 & January \\
\hline 267.80 & 115.33 & 0.044 & February \\
\hline 268.77 & 97.46 & 0.044 & March \\
\hline 372.55 & 160.25 & 0.049 & April \\
\hline 535.68 & 199.36 & 0.049 & May \\
\hline 534.27 & 213.96 & 0.049 & June \\
\hline 628.44 & 248.91 & 0.057 & July \\
\hline 563.72 & 251.22 & 0.057 & August \\
\hline 529.11 & 248.39 & 0.057 & September \\
\hline
\end{tabular}

Table 3. Storage of the reservoir for flood control in the NSGA-II method.

\begin{tabular}{cccc}
\hline $\begin{array}{c}\text { Total storage } \\
\left(\mathrm{Mm}^{3}\right)\end{array}$ & $\begin{array}{c}\text { Piraqi reservoir } \\
\left(\mathrm{Mm}^{3}\right)\end{array}$ & $\begin{array}{c}\text { Ostoor reservoir } \\
\left(\mathrm{Mm}^{3}\right)\end{array}$ & Month shift to the very right \\
\hline 3168.13 & 550.68 & 2617.45 & February \\
3178.57 & 481.32 & 2697.25 & March \\
2742.36 & 373.69 & 2368.67 & April \\
1872.88 & 32.58 & 1840.30 & May \\
\hline
\end{tabular}

Table 4. Storage of the reservoir to flood control in the MOPSO method.

\begin{tabular}{cccc}
\hline $\begin{array}{c}\text { Total storage } \\
\left(\mathrm{Mm}^{3}\right)\end{array}$ & $\begin{array}{c}\text { Piraqi reservoir } \\
\left(\mathrm{Mm}^{3}\right)\end{array}$ & $\begin{array}{c}\text { Ostoor reservoir } \\
\left(\mathrm{Mm}^{3}\right)\end{array}$ & Month as above \\
\hline 2978.13 & 560.68 & 2417.45 & February \\
3058.57 & 461.32 & 2597.25 & March \\
2912.36 & 343.69 & 2568.67 & April \\
1675.88 & 35.58 & 1640.30 & May \\
\hline
\end{tabular}

Table 5. The results of the two presented algorithms.

\begin{tabular}{ccl}
\hline MOPSO & NSGA-II & \\
\hline 6.9 & 8.9 & Income from electricity (MRial) \\
10.62 & 10.96 & $\begin{array}{l}\text { Storage of flood control } \\
\left(\mathrm{Gm}^{3}\right)\end{array}$ \\
\hline
\end{tabular}




\section{CONCLUSION}

In this paper we applied and compared NSGA-II and MOPSO algorithms for optimization of a system operation with two reservoirs. According to the results, it can be concluded that according to the stop conditions, which is the same for the two algorithms, the NSGA-II is performed better than the MOPSO algorithm. And according to Table 5 it can be see that the income from electricity and storage of flood control increased by: $22 \%$ and $3 \%$, respectively, using NSGA-II.

Some of the most important factors involved in this superiority are mutation operator and appropriate distribution of the population that prevented entrapment of the algorithm in local optimum points. The crowding distance operator for NSGA-II during the selection had a very good performance and the population diversity in different generations was well preserved. It is suggested that the proposed NSGA-II be used to optimize multi-objective system operation with more reservoirs.

\section{REFERENCES}

Adeyemo, J.A., 2011. Reservoir operation using multiobjective evolutionary algorithm - A review. Asian Journal of Scientific Research, 4, 1, 16-27. DOI: 10.3923/ajsr.2011.

Ajibola, A.S., Adewumi, A.O., 2014. Review of population based meta-heuristics in multi-objective optimization problems. International Journal of Computing, Communications \& Instrumentation Engineering (IJCCIE), $1,1,126-128$.

Baltar, A.M., Fontane, D.G., 2006a. A Multi-objective Particle Swarm Optimization Model for Reservoir Operations and Planning. In: Proceedings of Joint International Conference on Computing and Decision Making in Civil and Building Engineering, 14-16 June 2006, Montréal-Canada.

Baltar, A.M., Fontane, D.G., 2006b. A generalized multiobjective particle swarm optimization solver for spreadsheet models: application to water quality. In: Proceedings of Hydrology Days, March 2006, Fort Collins, Colorado, USA, $1-12$.

Bianchi, L. Dorigo, M., Gambardella, L.M., Gutjahr, W.J., 2009. A survey on meta-heuristics for stochastic combinatorial optimization. Natural Computing: An International Journal, 8, 2, 239-287.

Blum, C., Roli, A., 2003. Meta-heuristics in combinatorial optimization: Overview and conceptual comparison. ACM Computing Surveys, 35, 3, 268-308.

Chang, L.C., Chang, F.J., 2009. Multi-objective evolutionary algorithm for operating parallel reservoir system. Journal of Hydrology, 377, 12-20.

Chen, S.W., Chiang, T.C., 2014. Evolutionary many-objective optimization by MO-NSGA-II with enhanced mating selection. In: Proceedings of IEEE World Congress on Computational Intelligence (WCCI), pp. 1397-1404.

Eberhart, R., Kennedy, J., 1995. A new optimizer using particle swarm theory. In: Proceedings of IEEE Sixth International Symposium on Micro Machine and Human Science, 4-6 October 1995, Japan.

Fallah-Mehdipour, E., Bozorghaddad, O., Marino, M.A., 2011. MOPSO algorithm and its application in multipurpose multireservoir operations. Journal of Hydroinformatics, 13, 4, 794-811.

Ishibuchi, H., Tsukamoto, N., Nojima, Y., 2008. Evolutionary many-objective optimization: A short review. In: Proceedings of IEEE Congress on Evolutionary Computation, 1-6 June 2008, Hong Kong.
Kalyanmoy, D., Jain, H., 2012. Handling many-objective problems using an improved NSGA-II procedure. In: Proceedings of IEEE Congress on Evolutionary Computation (CEC) 2012.

Kalyanmoy, D., Agrawal, S., Pratap, A., Meyarivan, T., 2002. A fast and elitist multi-objective genetic algorithm: NSGAII. IEEE Transactions on Evolutionary Computation, 6, 2, 182-197.

Kennedy, J., Eberhart, R.C., 1995. Particle swarm optimization. In: Proceedings of IEEE International Conference on Neural Network, 27 November to 1 December 1995, Perth, WA.

Konak, A., Coit, D., Smith, E., 2006. Multi-objective optimization using genetic algorithms, a tutorial. Reliability Engineering and System Safety, 91, 9, 92-107.

Kumar, V., Minz, S., 2014. Multi-objective particle swarm optimization: an introduction. Smart Computing Review, 4, 5, 335-353.

Malekmohammadi, B., Zahraie, B., Kerachian, R., 2011. Ranking solution of multi-objective reservoir operation optimization models using multi-criteria decision analysis. Expert Systems with Applications, 38, 7851-7863.

Moore, J., Chapman, R., 1999. Application of particle swarm to multi-objective optimization. Technical report. Department of Computer Science and Software Engineering, Auburn University, Auburn, Alabama, USA.

Ostadrahimi, L., Mariño, M.A., Afshar, A., 2011. Multireservoir operation rules: Multi-swarm PSO-based optimization approach. Water Resource Management, 26, 407-427.

Patil, D.D., Dangewar, B.D., 2014. Multi-objective particle swarm optimization (MOPSO) based on Pareto dominance approach. International Journal of Computer Applications. 107, 4, 13-15.

Reddy, M.J., Kumar, D.N., 2007. Multi-objective particle swarm optimization for generating optimal trade-offs in reservoir operation. Hydrological Processes, 21, 21, 2897-2909.

Reddy, M.J., Kumar, D.N., 2009. Performance evaluation of elitist-mutated multi-objective particle swarm optimization for integrated water resources management. Journal of Hydroinformatics, 11, 1, 79-88.

Rio, G.L., D’Souza, K., Sekaran, C.H., Kandasamy, A., 2010. Improved NSGA-II based on a novel ranking scheme. Journal of Computing, 2, 2, 91-95.

Schaffer, J.D., 1985. Multiple objective optimization with vector evaluated genetic algorithms. In: Proceedings of the $1^{\text {st }}$ International Conference on Genetic Algorithm and their applications, 2 April 1985, Hillsdale, NJ, USA.

Shuai, W., Xiaohui, L., Xiaomin, H., 2012. Multi-objective optimization of reservoir ood dispatch based on MOPSO algorithm, In: Proceedings of 8th International Conference on Natural Computation, 29-31 May 2012, China.

Srinivas, N., Kalyanmoy, D., 1994. Multi-objective optimization using non-dominated sorting in genetic algorithms. Evolutionary Computation, 2, 3, 221-248.

Yang, J., 2012. A new particle swarm optimization Aalgorithm to hierarchy multi-objective optimization problems and its application in optimal operation of hydropower stations. Journal of Computers, 7, 8, 2039-2046.

Yusoff, Y., Ngadiman, M.S., Zain, A.M., 2011. Overview of NSGA-II for optimizing machining process parameters. Journal of Procedia Engineering, 15, 3978-3983.

Received 28 December 2016 Accepted 19 September 2017 